\title{
Agreement, dependencies, and Surface Correspondence in Obolo and beyond
}

\author{
Wm. G. Bennett \\ Department of English Language and Linguistics, Rhodes University, South Africa \\ Email: w.bennett@ru.ac.za
}

\begin{abstract}
Obolo, a lower cross-river language spoken in the Niger Delta, exhibits an implicational dependency between the onset and coda of a syllable: if a syllable has a nasal onset, then it cannot also have an oral coda (Faraclas 1984, Rowland-Oke 2003). Vowel nasalisation facts reveal this to be a long-distance, consonant-to-consonant interaction. Vowels are predictably nasalised before a nasal consonant, but not after one, so the ban on disharmonic NVT syllables cannot be attributed to incremental local spreading of nasality to attain a long-distance result. The analysis proposed here explains the Obolo facts using the theory of Surface Correspondence (Rose and Walker 2004, Hansson 2010a, Bennett 2013) as similarity-driven agreement. Limits on this agreement prevent it from applying in certain conditions, which cause it to present as a one-way dependency rather than full bidirectional agreement. These limitations fall out from pre-existing concepts in the harmony literature, namely position control and value dominance. The combination of these two effects in the same harmony system can serve to derive certain implicational dependencies from the same mechanism as agreement. This approach seems quite generalisable, as this paper demonstrates by applying it to a long-distance voicing dependency in Afrikaans (Coetzee 2014), in which root-medial voiced obstruents may not occur when this would produce disagreement with a voiceless root-initial obstruent.
\end{abstract}

Keywords: harmony, nasality, Obolo, long-distance, agreement, phonology, Afrikaans

\section{Introduction}

Obolo is an Andoni language spoken in the southeastern part of the Niger Delta, in southern Nigeria (Faraclas 1984, Rowland-Oke 2003). The language has a pattern of "static" nasal agreement within syllables, which is the focus of this paper. The basic observation, made initially by Faraclas (1984:xvi), is summarised in (1).

(1) "If the initial consonant is a nasal consonant, the final consonant must also be nasal." (Faraclas 1984:xvi) 
Obolo doesn't have productive morphemes of the right shapes to exhibit systematic alternations based on this pattern, but it's observed robustly as a gap in the syllable inventory of the language, schematised in (2) and exemplified in (3). Obolo has syllables that start with nasal onsets, as in (3a). It also has syllables that end in oral codas (3b). However, syllables that have both a nasal onset and an oral coda (3c) are not found in the language.

(2) Obolo CVC syllable inventory $(\mathrm{T}=$ oral consonant, $\mathrm{N}=$ nasal consonant, $\mathrm{V}=$ vowel $)$

\begin{tabular}{|l|l|l|}
\cline { 2 - 3 } \multicolumn{1}{c|}{} & Oral coda & Nasal coda \\
\hline Oral onset & ${ }^{`}[\text { TVT }]_{\sigma}$ & ${ }^{\checkmark}[\text { TVN }]_{\sigma}$ \\
\hline Nasal onset & ${ }^{*}[\mathbf{N V T}]_{\sigma}$ & ${ }^{\checkmark}[\mathrm{NVN}]_{\sigma}$ \\
\hline
\end{tabular}

(3) Examples (from Faraclas 1984):

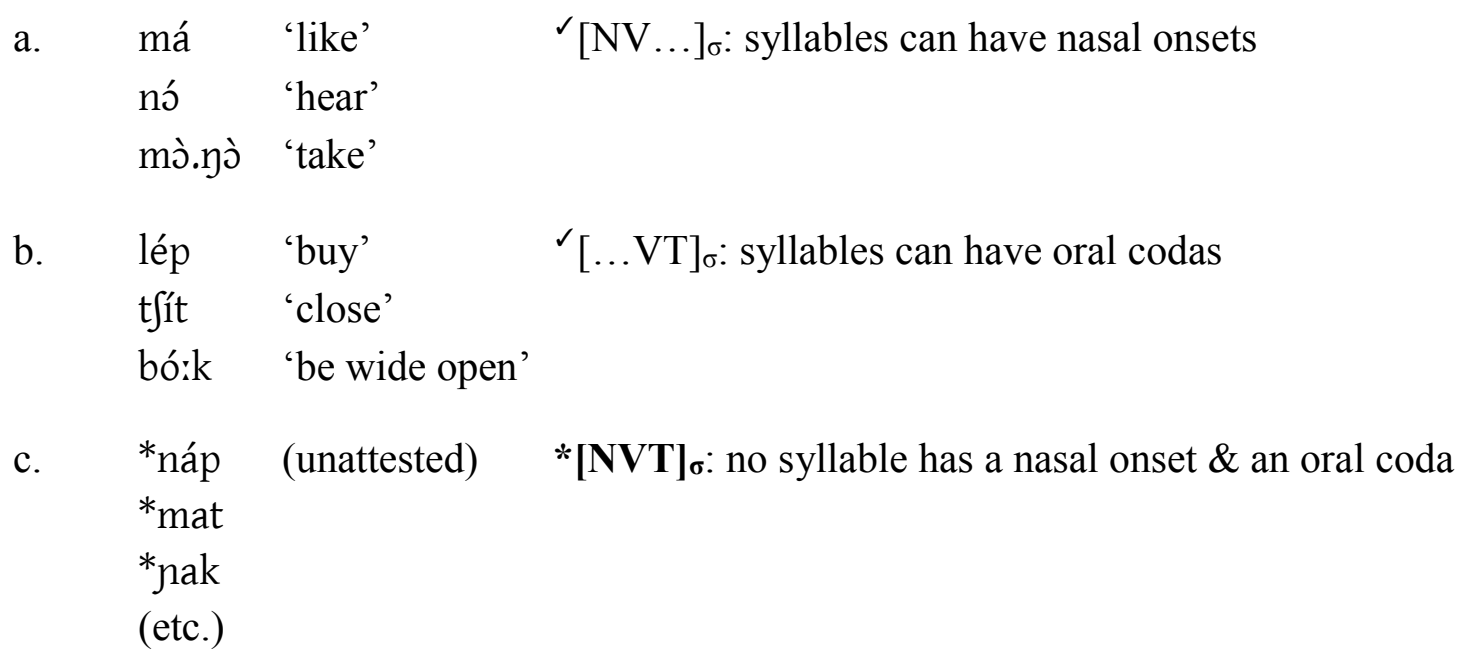

\subsection{A long-distance interaction}

Obolo's nasal agreement is a direct consonant-to-consonant interaction, and therefore a longdistance interaction; this is evident from the behaviour of nasality in vowels. Vowels in Obolo are predictably nasalised when they come before a nasal consonant, as in (4) (examples from Faraclas 1982).

(4) Obolo vowel nasalisation: Nasality spreads before nasals, but not after them

$$
\begin{aligned}
& \text { a. /ama + i-wa/ } \rightarrow \text { [ãmewa] *ãmẽwa 'many towns' }
\end{aligned}
$$

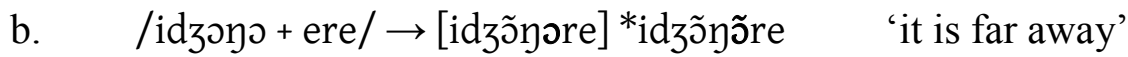

One possible interpretation for the nasal agreement generalisations in (2) and (3) is local spreading (see Walker 1998, Gafos 1999, Baković 2000, Ní Chiosáin and Padgett 2001, among others who discuss this general approach). Under this interpretation, the lack of disharmonic NVT syllables is the result of nasality spreading rightward from nasal onsets, up to the right 
edge of the syllable. So, [NVT] syllables are not found on the surface, because spreading turns underlying /NVT/ syllables into [NṼN] sequences, with nasality applied throughout ${ }^{1}$.

Interpreting this agreement as spreading allows it to be treated as a strictly local interaction: nasality spreads from the onset to the following vowel, and then from the vowel to the coda. This kind of analysis is appealing in that it requires no special theoretical machinery beyond simple local spreading of features. But, it gives the wrong result for examples like those in (4). If nasality spreads to the right edge of the syllable, then the post-nasal vowel in [ã.me.wa] should be nasal - but it isn't. The pattern we observe is a dependency between the onset and the coda ('if the onset is nasal, then the coda is nasal'), and a dependency between the coda and the nucleus ('if there is a syllable-final nasal, then the vowel before is nasalised'), but there is no dependency between the onset of a syllable and the following vowel - if the onset of a syllable is nasal, it is not necessarily the case that the vowel is nasal as well.

Because the nasal consonant agreement in Obolo is an interaction between the consonants directly, and is not mediated by the intervening vowel, it follows that it is an interaction between non-adjacent segments. Long-distance interactions of this sort require a departure from the strict locality hypothesis advocated by Ní Chiosáin and Padgett (2001) and others.

\subsection{Proposal}

The central proposal in this paper is that the Obolo nasal agreement pattern is explained by the theory of Surface Correspondence (SCorr; see Rose and Walker 2004, Hansson 2010a, Bennett 2013), previously applied to many other cases of long-distance consonant-to-consonant harmony.

The core intuitions behind the proposed analysis work as follows. Obolo requires consonants in the same syllable to agree in nasality. This agreement works through correspondence motivated by similarity, in the form of a shared feature: the consonants that crucially engage in this agreement share the feature [-continuant]. The absence of disagreeing syllables on the surface is explained in the same general way as in the spreading approach laid out above: NVT syllables are banned because they are forced to assimilate to NVN ones. Where this approach departs from the spreading analysis is the use of correspondence and similarity - rather than simple segmental adjacency - as the driving factor behind the assimilation.

The proposed analysis of Obolo has intriguing ramifications for the theory of consonant harmony more generally. The agreeing consonants in Obolo are very close together, and agreement between them can have an observable effect on the intervening vowel. In short, then, it doesn't look like typical cases of long-distance consonant harmony. But, crucially, it is readily explained by the same theory, without added stipulation. This shows that the theory of Surface Correspondence has broader applications than the early literature took to be so. Moreover, the

\footnotetext{
${ }^{1}$ The data gives no intrinsic reason why it needs to be spreading of nasality rather than retraction or loss of nasality; [TVT] and [NVN] syllables are both found in Obolo, and without visible alternations, there is no way to know which of these the illicit /NVT/ syllables get repaired to. There are reasons to think spreading of nasality is more plausible in this case, though: spreading of nasality appears to be an areal feature commonly found in other languages of the Niger Delta (e.g. Ijọ and Gokana - see Walker 1998); it is also far more common crosslinguistically than spreading of orality. The proposed analysis happens to derive this outcome, as we shall see later on.
} 
pattern we find in Obolo is a dependency: disagreeing TVN syllables are permitted, even while the reverse order $*$ NVT is not. This dependency situation emerges naturally from the theory, simply from the coming together of several different restrictions on assimilation.

\subsection{Structure of this paper}

The paper is organised in the following way: in $\S 2$, I present empirical and theoretical background on consonant harmony and the theory of Surface Correspondence. $\S 3$ explores the Obolo facts in more detail, and shows how they support the generalisations presented above, and how they permit a correspondence-driven analysis. $§ 4$ presents the Surface Correspondence analysis, and shows how it derives the correct pattern for Obolo. $\S 5$ compares this analysis to a more detailed spreading account, and $\$ 6$ provides a concluding discussion and connects the proposal for Obolo to the broader picture of deriving agreement-related dependencies generally.

\section{Background}

\subsection{Empirical side: long-distance consonant harmony}

Long-distance consonant assimilation is not very common cross-linguistically, but numerous cases have been identified by recent work on the typology of the phenomenon (Rose and Walker 2004, Hansson 2010a). Some examples are given below for illustration.

The most common kind of consonant harmony is sibilant harmony. In some languages, sibilant harmony propagates features only represented in sibilants. For instance, in Kinyarwanda, only sibilants robustly contrast for retroflexion, and sibilants in the same stem must agree for this property (5). But it's also possible for harmony among a class of segments to propagate a feature that isn't dependent on that class. Sibilant harmony in Tamajaq Tuareg (6) is an example: sibilants in the same stem agree not just for anteriority, but also for voicing - a feature which is also contrastive for other non-sibilant obstruents. In canonical examples of consonant harmony like these, we find agreement between non-adjacent segments that isn't mediated by the consonants that stand between them - unlike in spreading-based models.

(5) Kinyarwanda: Retroflexion harmony (Kimenyi 1979, Walker et al. 2008) non-retroflex sibilants $/ \mathrm{s} \mathrm{z} /$ become retroflex [s z] before another $/ \mathrm{s} z /$ in the stem

a. $\quad /$ ku-sas-a/ $\rightarrow$ gu〈sasa $\quad$ 'to make the bed' (root /-sas-/ 'make the bed'; has underlying /s/, not /s/)

b. $\quad /$ ku-sas-iis-a/ $\rightarrow$ gu〈sasiisa 'to cause to make the bed' $(/ \mathrm{s} / \rightarrow[\mathrm{s}]$ assimilation with /s/ in suffix /-iis/; *[gu〈sasiisa $)]$

(6) Tamajaq Tuareg: Voicing and Anteriority harmony (Hansson 2010b) $\mathrm{s} /$ becomes $\left\{\mathrm{z} \int 3\right\}$ to match another $\left\{\mathrm{z} \int 3\right\}$ later in the stem

a. /s-əlməd/ $\rightarrow$ səlməd 'teach' (causative prefix is $/ \mathrm{s}-/$, normally comes out as [s]) 
b. $/ \mathrm{s}-\partial \mathrm{kləz}$ / $\rightarrow$ zəkləz $^{\varsigma} \quad$ 'cause to invent' $\left(/ \mathrm{s} / \rightarrow[\mathrm{z}]\right.$ voicing assimilation before $\left./ \mathrm{z}^{\complement} / ;{ }^{*}\left[\operatorname{səkləz} \mathrm{z}^{\complement}\right]\right)$

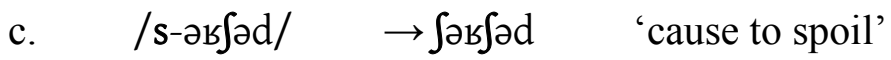
$\left(/ \mathrm{s} / \rightarrow\left[\int\right]\right.$ anterior assimilation before $/ \mathrm{S} / ; *\left[\right.$ səs $\left.\left.\int \partial \mathrm{d}\right]\right)$

d. /s-kuzət/ $\rightarrow$ zokuzat 'cause to saw' $(/ \mathrm{s} / \rightarrow[3]$ voicing and anterior assimilation before $/ 3 / ; *[$ səkuzət $])$

Long-distance consonant harmony is not unique to sibilants, though. In Lubukusu, for example, liquid consonants in the stem agree for the rhotic/lateral contrast, with according [r] [l] alternations (7). And in Kikongo (8), we find sonorants (liquids and nasals) in the same stem agreeing in nasality, with [l] [n] alternations in suffixes.

(7) Lubukusu: Rhotic harmony (Hansson 2010a, Rose and Walker 2004)

lateral $/ \mathrm{l} / \rightarrow$ rhotic $[\mathrm{r}]$ after another rhotic in the stem
a. /teex-il-a/ $\rightarrow$ teexela 'cultivate for' (applicative suffix /-il/ has /1/; *[teexera])
b. /resj-il-a/ $\rightarrow$ resjera 'retrieve for' $(/ \mathrm{l} / \rightarrow[\mathrm{r}]$ assimilation after rhotic $/ \mathrm{r} / ; *$ resjela $])$

(8) Kikongo: Nasal harmony (Ao 1991; see also Walker 2000, Rose and Walker 2004) non-nasal sonorant $/ \mathrm{l} / \rightarrow$ nasal $[\mathrm{n}]$ after another nasal in the stem
a. /sakid-il-a/ $\rightarrow$ sakidila 'congratulate for' (applicative suffix /-il/ has /1/; *[sakidina])
b. $\quad$ /dumuk-il-a/ $\rightarrow$ dumukina 'jump for' $\left(/ \mathrm{l} / \rightarrow[\mathrm{n}]\right.$ assimilation after nasal $/ \mathrm{m} / ;{ }^{*}$ [dumukila] $)$

These examples all involve agreement throughout the morphological stem, but other consonant harmony systems are more limited. In Ndonga, for instance, we find nasal consonant harmony very much like that seen in Kikongo, but with one further condition: agreement is only enforced between consonants in adjacent syllables (9). Koyra (10) illustrates a comparable effect in sibilant harmony: it has anteriority harmony like we find in Tamajaq Tuareg, but with the added limit that sibilants only agree when they are 'transvocalic' (in the sense of Hansson 2010a) i.e. only when they are in the same CVC sequence.

(9) Ndonga: Nasal harmony like Kikongo, with a one-syllable distance limit (Fivaz and Shikomba 1986)
a. /kun-il-a/ $\rightarrow$ ku.ni.na 'sow for'
$(/ \mathrm{l} / \rightarrow[\mathrm{n}]$ nasal assimilation in adjacent syllables; $*$ [ku.ni.na])
b. /nik-il-a/ $\rightarrow$ ni.ki.la $\quad$ 'season for'
(No nasal assimilation between non-adjacent syllables; *[ni.ki.na])


(10) Koyra: Sibilant harmony, but only across one intervening vowel (Hansson 2010a)
a.

$$
\begin{aligned}
& \text { /gi:3:-os:o/ } \rightarrow \text { girz:of:o } \quad \text { 'it suppurated' } \\
& (\text { suffix } / \mathrm{s} / \rightarrow[S] \text { anterior assimilation after [3]; *[gi:z:os:o]) }
\end{aligned}
$$
b. /Sod-osio/ $\rightarrow$ Sodios:o 'he uprooted'
(No anterior assimilation except in CVC sequences; *[Sodiof:o])

The point of these examples is to demonstrate that the notion of non-local agreement between consonants is empirically well-precedented. I will claim that Obolo is an instantiation of the same phenomenon, just a less obvious example.

\subsection{Theoretical side: Surface Correspondence theory}

The general theoretical framework assumed here is Optimality Theory (OT; Prince and Smolensky 2004), a model in which phonology is understood as mapping inputs to outputs, using the mechanism of choice from among a set of alternative candidates. The choice of one candidate as optimal depends on the language-specific ranking of a set of universal, violable, constraints.

Recent work on long-distance consonant harmony uses the more specific theory of Surface Correspondence (Rose and Walker 2004, Hansson 2010a, Bennett 2013). The basic idea works like this: first, the surface (output) consonants in a word can be in correspondence relationships with each other. Second, these correspondence structures matter - they can affect how inputs are mapped to outputs in the phonology of a language. This happens because there are constraints that are sensitive to Surface Correspondence structures. Thus, whether two consonants correspond or not affects their constraint violation profiles, which in turn affects how they relate to each other in terms of the evaluation of one candidate as optimal. For the purposes of this paper, I represent Surface Correspondence structures using set notation. Thus, an input $/ \mathrm{t}$...d/ can surface faithfully either with correspondence, as [t...d], \{t d $\}$, or without correspondence, as [t...d], $\{\mathrm{t}\}\{\mathrm{d}\}$; or, it can surface unfaithfully, with one or the other consonant deviating from its underlying counterpart - and these deviations can be motivated by improvements on the constraints that assess correspondence structure.

(11) Example: an underlying form /t...d/ can map to outputs such as these:

\begin{tabular}{|l|ll|l|}
\hline & Surface form, & SCorr structure & Remarks \\
\hline a. & {$[\mathrm{t} \ldots \mathrm{d}]$,} & $\{\mathrm{t}\}\{\mathrm{d}\}$ & Fully faithful, $\mathrm{t} \& \mathrm{~d}$ don't corr. \\
\hline b. & {$[\mathrm{t} \ldots \mathrm{d}]$,} & $\{\mathrm{t} \mathrm{d}\}$ & Fully faithful, $\mathrm{t} \& \mathrm{~d}$ do corr. \\
\hline c. & {$[\mathrm{t} \ldots \mathrm{t}]$,} & $\{\mathrm{t} \mathrm{t}\}$ & $/ \mathrm{d} / \rightarrow[\mathrm{t}]$, and the two $[\mathrm{t}]$ s corr. \\
\hline d. & {$[\mathrm{k} \ldots \mathrm{d}]$,} & $\{\mathrm{k}\}\{\mathrm{d}\}$ & $/ \mathrm{t} / \rightarrow[\mathrm{k}], \mathrm{k} \& \mathrm{~d}$ don't corr. \\
\hline
\end{tabular}

The constraints that assess candidates based on their Surface Correspondence structures fall into two categories. The first group is the family of CORR $[\alpha \mathrm{F}]$ constraints: these demand correspondence among consonants which share the specified feature (or group of features) ' $[\alpha \mathrm{F}]$ '. They are of the form 'if two consonants are both $[\alpha \mathrm{F}]$, then they correspond with each other'. Thus, they have an implicational structure, and demand correspondence on the basis of similarity. 
The other group of correspondence-related constraints is the CC.Limiter constraints, which impose limits on correspondence. The most important of these constraints, for the present analysis, is the CC.IDENT family, which requires correspondents to agree. CC.IDENT constraints are of the form 'if consonants $X$ and $Y$ correspond, then they agree for $[ \pm G]$ '. Thus, by working together with CORR constraints, CC.IDENT constraints can cause similarity in one feature to spur agreement in another feature. If consonants share one feature, $[ \pm \mathrm{F}]$, then they must correspond (the work of a CORR constraint), and because they correspond, they must also agree in another feature, $[ \pm \mathrm{G}]$, in order to satisfy $C C \cdot$ IDENT- $[ \pm G]$. Other $C C \cdot$ Limiter constraints restrict correspondence in other ways, e.g. structurally, for example by prohibiting correspondence between consonants that are too far apart (rather than by prohibiting correspondence based on disagreement).

\subsection{Harmony and similarity}

The Surface Correspondence theory of harmony comes with very clear predictions. One of these is that long-distance agreement must be based on some kind of similarity. CC - IDENT constraints only require agreement between consonants which correspond. CORR constraints only require correspondence between consonants that are somehow similar. Consequently, this type of agreement must be parasitic on some essential similarity between the interacting segments.

The examples of consonant harmony presented above all fit the profile of one kind of similarity spurring another. In Lubukusu, we find agreement between consonants that share the feature $[+ \text { liquid }]^{2}$. In Kinyarwanda and Tamajaq Tuareg, we find agreement among the class of sibilants. In Kikongo and Ndonga, agreement holds only among [+sonorant] consonants. Based on this, we can ask: does Obolo also fit this profile? Are the onsets and codas that undergo agreement united by some kind of similarity in the first place? The answer is yes, they do have a common feature, as we shall see in the next section.

\section{Obolo in a bit more detail}

\subsection{Basics of Obolo phonology}

The consonant inventory of Obolo is given in the table in (12).

Obolo consonant inventory (following Rowland-Oke 2003:22)

\begin{tabular}{|c|c|c|c|c|c|}
\hline & Labial or Labio-velar & Alveolar & Palatal & Velar & Glottal \\
\hline Stop & $\begin{array}{rl}p & b \\
k \hat{k p} & g b\end{array}$ & $\mathrm{t} d$ & c 1 & $\begin{array}{rl}\mathrm{k} & \mathrm{g} \\
\mathrm{k}^{\mathrm{w}} & \mathrm{g}^{\mathrm{w}}\end{array}$ & (?) \\
\hline Fricative & $\mathrm{f}$ & $\mathrm{s}(\mathrm{z})$ & & & (h) \\
\hline Nasal & $\mathrm{m}$ & $\mathrm{n}$ & $\mathrm{n}$ & $\begin{array}{l}y \\
y^{w}\end{array}$ & \\
\hline Approximant & & $1 \mathrm{r}$ & $\mathrm{j}$ & $\mathrm{W}$ & \\
\hline
\end{tabular}

Syllables in Obolo consist minimally of a vowel or syllabic nasal (V or N), and are maximally CV:C in size (Faraclas 1984). There are strict restrictions on coda consonants, though. The only

\footnotetext{
${ }^{2}$ The feature [+liquid] here could also be understood as a cover term for [+consonantal, +sonorant, - nasal]; the existence of a single '[ \pm liquid]' feature isn't key to the relative similarity that spurs the harmony.
} 
consonants permitted in coda positions are those in bold in the table above: they are the voiceless stops $[\mathrm{pt} k]$ and the nasals [ $\mathrm{m} \mathrm{n} \mathrm{y}]$.

The set of coda consonants allowed in Obolo all share a common feature: they are all [-continuant]. This means that in any closed syllable, the coda is necessarily a non-continuant. This is the similarity that the Surface Correspondence theory leads us to expect. In the hypothetical /NVT/ syllables that are crucially repaired by harmony (thereby guaranteeing the lack of [NVT] surface syllables), the onset and coda are both [-continuant]. So, the nucleus of similarity in this system is [-continuant], and the analysis will cause similarity in this respect to drive a need for similarity in the feature $[ \pm$ nasal $]-$ i.e. forcing nasal agreement.

\subsection{The empirical basis for the agreement pattern}

The point of this section is to demonstrate how the facts of Obolo support the characterisation of the pattern asserted in $\S 1$. Recall that the core generalisation of the Obolo agreement pattern is the following: if a syllable has a nasal onset, then its coda must also be nasal. Thus, closed syllables of the forms TVT, NVN, and TVN are all permitted; examples of each are given in (13). What's impossible in Obolo are syllables of the form *NVT; all of the possible combinations of a nasal onset with one of the permitted oral codas are unattested (14).

(13) Licit CVC syllables in Obolo:
a. $\quad \checkmark[$ fùk $]$
'read'
b. ' $\quad$ bén]
'carry'
$\checkmark$ TVT $]_{\sigma}$
c. $\quad \checkmark$ nám]
'sell'
$\checkmark[\mathrm{TVN}]_{\sigma}$
${ }^{\top}[\mathrm{NVN}]_{\sigma}$

(14) Impossible: $*[\mathrm{NVT}]_{\sigma}$ (syllables with nasal onset and an oral coda)
a. $\quad{ }^{*}$ map, ${ }^{*}$ mat, ${ }^{*}$ mak
b. $\quad *_{\text {nap, }}^{*}$ nat, *nak
c. * *nap, *nat, *nak
d. $\quad *_{\text {yap, }}^{*}$ yat, * yak

The agreement generalisation for Obolo is explicitly identified in the phonology sections of two different Obolo grammars, written in different languages and decades apart (Faraclas 1984, Rowland-Oke 2003). I have not found any counter-examples in either grammar, or in my search of other papers on Obolo (Aaron 1996/1997a,b; Faraclas 1982).

The nasal agreement pattern in Obolo is a generalisation about the form of syllables, not the form of CVC sequences in general. In fact, the language does allow NVT sequences on the surface, when these consonants are syllabified as the onsets of two consecutive syllables. Some examples are given in (15). No agreement holds across the edge of the syllable; this parallels other cases of consonant harmony noted in $\S 2$ above, such as Kinyarwanda (5), Lubukusu (7), and Kikongo (8), where agreement holds only within the stem domain, and not across its edge. 
(15) Nasal agreement does not hold across syllable edges.
a. tú.mù.kâ
$(\nrightarrow$ *tu.mu.na, *tu.bu.ka)
'instead of'
b. nì.ná.lék
( $\nrightarrow$ *ni.na.nek, *ni.la.lek)
'complain'
c. í.mù.mè.tfjèn
$\left(\nrightarrow *^{*}\right.$ i.mu.me.njen)
d. ú.má.nè.bót
$\left(\nrightarrow *^{*}\right.$ u.ma.ne.mot)
e. à.náǹ.jìn
$(\nrightarrow *$ a.nan.nin)
'love'
'she-goat'
'fly'

\section{Applying the Surface Correspondence theory to Obolo}

We turn now to the formal analysis of the pattern, in terms of candidates, correspondence structures, and constraint rankings.

\subsection{The Surface Correspondence interpretation of the pattern}

Interpreted in terms of Surface Correspondence, the Obolo pattern is understood as in (16). This set of premises is expressed by a grammar that makes the constellation of mappings given in (17), both in schematic form, and with representative examples of each case.

(16) Obolo generalisations, rephrased in terms of correspondence:

a. Non-continuants in the same syllable must correspond

b. Correspondents must agree in nasality (and assimilate to do so, if needed)

c. But, no agreement happens between an oral onset and a nasal coda

(TVN syllables occur; something prevents them from harmonising - see $§ 4.5$ )

(17) Input-Output mappings crucial to the Obolo pattern (with examples):

\begin{tabular}{|c|c|c|c|}
\hline & Input & Output, SCorr classes & Remarks \\
\hline a. & $\begin{array}{l}\text { /NVT/ } \\
\text { nap (hypothetical) }\end{array}$ & $\begin{array}{l}\text { [NVN], } \\
\text { [nam }]\end{array}$ & $\begin{array}{l}\text { Disagreeing NVT syllables are forced } \\
\text { to harmonise (to NVN ones) }\end{array}$ \\
\hline$b$ & $\begin{array}{l}\text { /NVTV/ } \\
\text { túmùkâ 'instead of' }\end{array}$ & 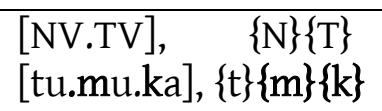 & $\begin{array}{l}\text { Across syllable edges there is no } \\
\text { correspondence, so no agreement }\end{array}$ \\
\hline c. & $\begin{array}{l}\text { /TVN/ } \\
\text { bén 'carry' }\end{array}$ & $\begin{array}{l}\text { [TVN], } \\
\text { [ben], }\end{array}$ & $\begin{array}{l}\text { Disagreeing TVN syllables have } \\
\text { correspondence, no agreement }\end{array}$ \\
\hline $\mathrm{d}$ & $\begin{array}{l}\text { /TVT/ } \\
\text { lép 'buy' }\end{array}$ & $\begin{array}{l}\text { [TVT], } \\
\text { [lep], }\end{array}$ & \multirow{2}{*}{$\begin{array}{l}\text { Agreeing syllables surface faithfully, } \\
\text { with correspondence }\end{array}$} \\
\hline e. & $\begin{array}{l}\text { /NVN/ } \\
\text { mǎn 'birth' }\end{array}$ & $\begin{array}{l}{[\mathrm{NVN}]} \\
{[\mathrm{man}]}\end{array}$ & \\
\hline
\end{tabular}

The following subsection shows how this grammar is derived in OT, using correspondence constraints. 


\subsection{Constraints responsible for the basic agreement}

The constraints responsible for the basic agreement pattern in Obolo are defined formally in (18) and (19). The relevant CORR constraint is CORR-CVC.[-continuant], which compels non-continuants to correspond. This constraint has the CVC domain as its scope, which means it only assesses correspondence for consonants in a 'transvocalic' configuration. This reflects the same CVC distance limit seen in the Ndonga and Koyra examples in $\S 2$ above.

(18) CORR-CVC.[-continuant]: 'If two non-continuants are in a CVC domain, they correspond' $D f n$ : For each distinct pair of output consonants, $\mathrm{X} \& \mathrm{Y}$, assign a violation if:
a. $\quad \mathrm{X} \& \mathrm{Y}$ are in the configuration ...CVC...,
and
b. $\quad \mathrm{X} \& \mathrm{Y}$ both have the feature specification [-continuant], and
c. $\quad \mathrm{X} \& \mathrm{Y}$ are not in the same surface correspondence class

(19) CC·IDENT-[nasal]: 'If two consonants correspond, then they agree for [ \pm nasal]'

$D f n$ : For each distinct pair of output consonants, $\mathrm{X} \& \mathrm{Y}$, assign a violation if:

a. $\quad \mathrm{X} \& \mathrm{Y}$ are in the same surface correspondence class, and

b. $\quad \mathrm{X} \& \mathrm{Y}$ have different specifications for $[ \pm$ nasal $]$

The combined effect of these two constraints is that non-continuant consonants in a CVC arrangement must agree in nasality, i.e. any CVC sequence can have two nasals, or two plosives, but not one of each. This effect emerges from both constraints being ranked above input-output faithfulness for nasality. This ranking is illustrated in (20), and motivated by the tableau in (21). If we apply this ranking to an input of the form $/ \mathrm{NVT} /$, it favours a candidate where the coda stop changes to a nasal (21a) over the alternatives where the sequence remains disharmonic $(21 b, 21 c)$.

(20) Essential ranking for harmony: CORR and CC·IDENT » Faithfulness for nasality

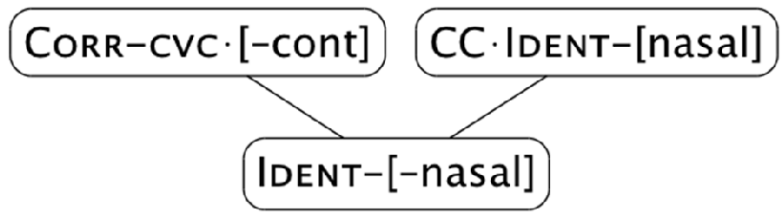

(21) This ranking produces nasal agreement in CVC sequences: $/ \mathrm{NVT} / \rightarrow[\mathrm{NVN}]^{3}$

\begin{tabular}{|c|c|c|c|c|c|}
\hline \multicolumn{2}{|c|}{$\begin{array}{l}\text { Input: nap } \\
\text { Output: nam, (not *nap) }\end{array}$} & $\begin{array}{c}\text { CoRR-CVC. } \\
{[- \text { continuant }]}\end{array}$ & $\begin{array}{l}\text { CC } \cdot \text { IDENT- } \\
{[\text { nasal] }}\end{array}$ & $\begin{array}{l}\text { IDENT- } \\
\text { [nasal] }\end{array}$ & Remarks \\
\hline a. & $\begin{array}{l}\text { [nam], } \\
\text { SCorr } \mathcal{R}:\{\mathrm{n} \mathrm{m}\}\end{array}$ & (0) & (0) & (1) & $\begin{array}{l}\text { Winner; NVT becomes } \\
\text { NVN; nasal agreement }\end{array}$ \\
\hline$\sim b$. & $\begin{array}{l}\text { [nap], } \\
\text { SCorr } \mathcal{R}:\{\mathrm{n} \mathrm{p}\}\end{array}$ & & $\begin{array}{c}\mathrm{W} \\
(0 \sim 1)\end{array}$ & $\begin{array}{c}\mathrm{L} \\
(1 \sim 0)\end{array}$ & $\begin{array}{c}\text { Faithful n p corr. Loses } \\
\text { on CC } \cdot \text { Ident-[nasal] }\end{array}$ \\
\hline$\sim \mathrm{C}$. & $\begin{array}{l}\text { [nap], } \\
\text { sCorr } \mathcal{R}:\{n\}\{p\}\end{array}$ & $\begin{array}{l}W \\
(0 \sim 1)\end{array}$ & & $\begin{array}{c}\mathrm{L} \\
(1 \sim 0)\end{array}$ & $\begin{array}{l}\text { Faithful non-corr. loses } \\
\text { on the CORR constraint }\end{array}$ \\
\hline
\end{tabular}

\footnotetext{
${ }^{3}$ The tableaux in this paper follow a hybrid comparative format (Prince 2002). The first row gives the winning candidate, and shows its constraint violations (using numbers rather than ${ }^{*}$ ). Other rows show alternatives, and
} 
The candidate in (21a) changes /nap/ to [nam]; the [n] and [m] correspond with each other, and they match for nasality. This is the winning output. The alternative in (21b) has correspondence without making any change; [n] corresponds with [p], but that's bad because they don't agree for nasality (thereby violating CC·IDENT-[nasal]). The other alternative in (21c) also keeps /nap/ as [nap], and has no correspondence between them. This is fine in terms of agreement; it satisfies CC·IDENT-[nasal] because the disagreeing consonants aren't in correspondence with each other. But, this lack of correspondence presents a different problem: the candidate in (21c) violates constraint CORR-CVC. [-continuant], since it has a nasal and a stop in a CVC sequence which fail to correspond. The result is that (21a) wins because it has correspondence between the non-continuants, and also has nasality agreement between the correspondents. So, under this constraint ranking, NVT syllables cannot show up on the surface; even if there is an underlying NVT sequence, it gets changed to NVN (which is allowed).

This agreement effect is the core of the analysis. It is not sufficient on its own, however. We turn now to expanding the explanation to handle other aspects of the Obolo pattern.

\subsection{The syllable-bounding effect}

The domain of the CORR constraint used in (21) is CVC sequences - just like in cases of 'transvocalic' harmony (such as Ndonga, from §2). But, this constraint is not sensitive to syllable boundaries; it favours agreement in any CVC sequence, not just syllable-internal ones. This is the wrong result for Obolo, where agreement is confined to within the syllable. This syllable-bounding effect is explained by the addition of another constraint, CC·EDGE- $(\sigma)$, defined in (22) (adapted from Bennett 2013).

(22) CC.EDGE- $(\sigma)$ : 'No correspondence across the edge of a syllable'

$D f n$ : For each distinct pair of output consonants, $\mathrm{X} \& \mathrm{Y}$, assign a violation if:

a. $\quad \mathrm{X} \& \mathrm{Y}$ are in the same surface correspondence class, and

b. $\quad \mathrm{X} \& \mathrm{Y}$ are not contained in the same syllable

When CC.EDGE- $(\sigma)$ dominates CORR-CVC $\cdot[-$ continuant], correspondence is not enforced in CVC domains that straddle the edge of a syllable. This ranking is illustrated in (23). The tableau in (24) shows how adding CC.EDGE- $(\sigma)$ in this way prevents harmony from extending across syllable edges in /NVTV/ sequences which don't agree. If correspondence isn't allowed to cross syllable edges, then agreement isn't required between consonants in different syllables. The input in this case is shown as /...muka/, a truncated representation of the word [túmùkâ] ('instead of'), showing only the consonants of interest.

how they fare as competitors against the Winner. The pairs of numbers in parentheses indicate the violation count of the winning candidate against the alternative Loser. ' $\mathrm{W}$ ' and ' $\mathrm{L}$ ' indicate that a given constraint prefers the Winner or Loser, respectively. Blank cells indicate that a constraint has no preference between the winner and that alternative - they have the same number of violations (usually 0 ). 


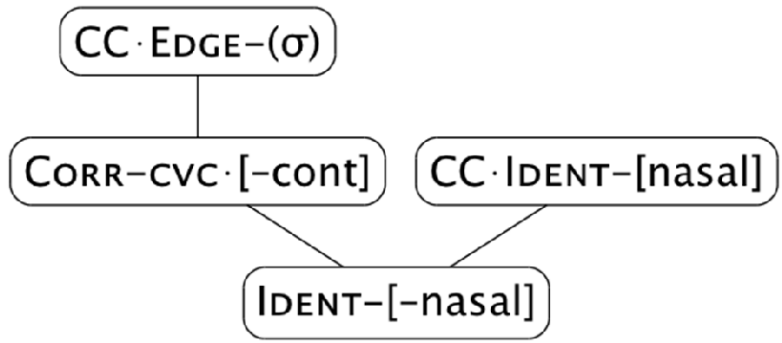

(24) CC.EDGE- $(\sigma)$ restricts the agreement to just syllable-internal CVC sequences

\begin{tabular}{|c|c|c|c|c|c|}
\hline \multicolumn{2}{|c|}{$\begin{array}{l}\text { Input: ...muka } \\
\text { Output: ...mu.ka }\end{array}$} & CC $\cdot \operatorname{EDGE}-(\sigma)$ & $\begin{array}{c}\text { CORR-CVC. } \\
{[- \text { continuant }]}\end{array}$ & $\begin{array}{c}\text { CC } \cdot \text { IDENT- } \\
\text { [nasal] }\end{array}$ & $\begin{array}{l}\text { IDENT- } \\
\text { [nasal] }\end{array}$ \\
\hline$\Leftrightarrow a$. & $\begin{array}{l}{[\ldots \mathrm{mu} . \mathrm{ka}]} \\
\mathcal{R}:\{\mathrm{m}\}\{\mathrm{k}\}\end{array}$ & (0) & (1) & (0) & (0) \\
\hline$\sim b$. & $\begin{array}{l}\text { [...mu.na], } \\
\mathcal{R}:\{\mathrm{m} \mathrm{n}\}\end{array}$ & $\begin{array}{c}\mathrm{W} \\
(0 \sim 1)\end{array}$ & $\begin{array}{c}\mathrm{L} \\
(1 \sim 0) \\
\end{array}$ & & $\begin{array}{c}\mathrm{W} \\
(0 \sim 1)\end{array}$ \\
\hline$\sim \mathrm{C}$. & $\begin{array}{l}{[\ldots \mathrm{mu} . \mathrm{ka}]} \\
\mathcal{R}:\{\mathrm{m} \mathrm{k}\}\end{array}$ & $\begin{array}{c}\mathrm{W} \\
(0 \sim 1)\end{array}$ & $\begin{array}{c}\mathrm{L} \\
(1 \sim 0)\end{array}$ & $\begin{array}{c}W \\
(0 \sim 1)\end{array}$ & \\
\hline
\end{tabular}

In this tableau, the winning candidate in (24a), which shows /tumuka/ $\rightarrow$ [tu.mu.ka] ("instead of'), has no correspondence between the $[\mathrm{m}]$ and $[\mathrm{k}]$. Since these are both non-continuants, and since they are in a CVC arrangement, the lack of correspondence between them violates CORR$\mathrm{CVC} \cdot[-$ continuant $]$. The alternatives in (24b) and (24c) perform better on this constraint: (24c) has the same surface form, but with correspondence between the [m] and [k]; (24b) has not just this correspondence, but also nasality agreement, mapping /tumuka/ to [tumuya]. However, while both of these candidates avoid violating CORR-CVC.[-continuant], they do so by having correspondence between consonants in different syllables; this runs afoul of the higher-ranked constraint $\mathrm{CC} \cdot \operatorname{EDGE}-(\sigma)$. So, by dominating the agreement constraints, $\mathrm{CC} \cdot$ EDGE- $(\sigma)$ restricts agreement, preventing it from crossing over syllable edges. The basic ranking of the bottom three constraints still favours agreement in this case $((24 b)$ is preferred over $(24 c)$ on CC - IDENT[nasal]); but, assimilating to achieve agreement is only optimal when it happens syllableinternally.

\subsection{Putting further limits on agreement: split IDENT constraints}

The analysis laid out so far requires non-continuants in the same syllable to agree in nasality. This explains the lack of NVT syllables on the surface. Syllables of this form don't satisfy the agreement requirement, and therefore are changed to one of the agreeing syllable shapes (by hypothesis, NVN) ${ }^{4}$.

\footnotetext{
${ }^{4}$ The analysis presented so far doesn't explain why /NVT/ inputs change to [NVN] surface forms, as opposed to [TVT] ones. Both options are licit in Obolo, and a grammar that does either mapping correctly derives the surface gap. The choice of NVN does fall out from an additional component of the analysis, explored in $\S 4.6$.
} 
Two outstanding issues remain before we arrive at a full explanation. First, Obolo does permit TVN syllables; why, then, is agreement not enforced in this case? Second, why should the banned *NVT syllables be repaired by nasalisation to NVN, and not by denasalisation to TVT? Both of these questions are answered by adopting two existing proposals about specialised faithfulness constraints.

The analysis sketched out above uses just one faithfulness constraint, IDENT-[nasal] (25), which penalises any input-output disparity with respect to the feature [ \pm nasal].

(25) IDENT-[nasal]: 'Don't change nasality'

$D f n$ : For each distinct pair of one output segment $\mathrm{X}$, and its input counterpart $\mathrm{X}$ ', assign a violation if:

a. $\quad \mathrm{X}^{\prime}$ is [ $\alpha$ nasal], and

b. $\quad \mathrm{X}$ is $[\neg \alpha$ nasal $]$

Expanding the analysis here requires splitting this constraint into a family of four constraints, closely related in form and function. These are defined in (26). The first two, IDENT-[-nasal] and IDENT-[+nasal], effect a split based on feature values, following Pater (1999), McCarthy and Prince (1999), and others. IDENT-[+nasal] prohibits changing underlying [+nasal] segments to [-nasal]; it is violated by denasalisation only, and not by nasalisation. Its converse is IDENT[-nasal], which similarly demands faithfulness for underlying [-nasal] values, but not underlying [+nasal] ones; it is violated by nasalisation, but not by denasalisation. So, in effect, this splits the single, monolithic, IDENT constraint of (25) into two parametric halves that penalise each conceivable direction of change.

\section{Split IDENT constraints:}

a. IDENT-[-nasal]: 'Don't change from [-nasal] to [+nasal]' (penalises $/ \mathrm{t} / \rightarrow[\mathrm{n}]$ )

b. IDENT-[+nasal]: 'Don't change from [+nasal] to [-nasal]' (penalises $/ \mathrm{n} / \rightarrow[\mathrm{t}]$ )

c. IDENT-Onset-[-nasal]: 'Don't change onsets from [-nasal] to [+nasal]'

d. IDENT-Onset-[+nasal]: 'Don't change onsets from [+nasal] to [-nasal]'

The last two constraints in (26), IDENT-Onset-[-nasal] and IDENT-Onset-[+nasal], are positional faithfulness constraints (Beckman 1998). They are like the general IDENT constraints, but apply only to consonants in onset positions.

Using the more articulated set of IDENT constraints in (26) allows the basic analysis of agreement to be limited further, producing the dependency effect, which we turn to now.

\subsection{Managing disagreement in TVN syllables}

The split IDENT constraints in (26) allow the analysis to be extended to explain why disagreement is permitted in TVN syllables, which are permitted in Obolo even though disagreement in the other direction is banned (*NVT). The key ingredients for the answer are IDENT-[+nasal] and IDENT-Onset-[-nasal]. The former penalises changing underlying nasals to oral consonants; it prohibits changing /TVN/ inputs to [TVT]. The latter penalises changing underlying oral onsets into nasal ones; it prohibits changing /TVN/ to [NVN]. When these two constraints are both ranked higher than the constraints that cause agreement to happen, the 
effect is that agreement happens only on limited terms: it's good to have nasal agreement, but not at the cost of changing oral onsets, and not at the cost of changing nasals to non-nasals. When these two limits are combined, the resulting effect is that even though disagreeing /TVN/ inputs pose an agreement problem, there is no way to fix the agreement violation without violating an even higher-ranked constraint. In other words, when the harmony constraints dominate only IDENT-[-nasal], and not IDENT-Onset-[-nasal] or IDENT-[+nasal], then agreement will only happen when it can be achieved just by changing oral codas to nasal.

The important ranking conditions are shown in the diagram in (27), and illustrated in the tableau in (28), using the word [bén] ('carry').

(27) Limits on harmony emerge from the agreement constraint CC.IDENT-[nasal] dominating IDENT-[-nasal], but not the other nasality faithfulness constraints:

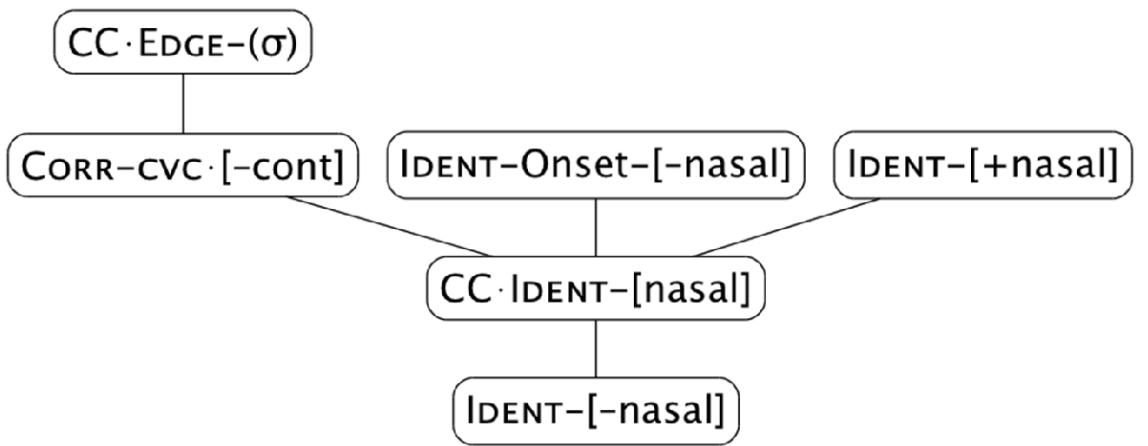

(28) Illustrative tableau

\begin{tabular}{|c|c|c|c|c|c|c|c|}
\hline \multicolumn{2}{|c|}{$\begin{array}{l}\text { Input: ben } \\
\text { Output: ben }\end{array}$} & $\begin{array}{l}\text { IDENT-Onset- } \\
{[- \text { nasal }]}\end{array}$ & $\begin{array}{c}\text { IDENT- } \\
{[+ \text { nasal }]}\end{array}$ & $\begin{array}{c}\text { CoRR-CVc } \cdot \\
{[- \text { continuant }]}\end{array}$ & $\begin{array}{c}\text { CC } \cdot \text { IDENT- } \\
{[\text { nasal }]}\end{array}$ & $\begin{array}{c}\text { IDENT- } \\
\text { [-nasal] }\end{array}$ & Remarks \\
\hline a. & $\begin{array}{l}{[\text { ben], }} \\
\mathcal{R}:\{\mathrm{b} \mathrm{n}\}\end{array}$ & (0) & (0) & (0) & (1) & (0) & $\begin{array}{c}\text { Corresp., but no } \\
\text { agreement }\end{array}$ \\
\hline$\sim \mathrm{b}$. & $\begin{array}{l}{[\mathrm{men}]} \\
\mathcal{R}:\{\mathrm{m} \mathrm{n}\}\end{array}$ & $\begin{array}{c}\mathrm{W} \\
(0 \sim 1)\end{array}$ & & & $\begin{array}{c}\mathrm{L} \\
(1 \sim 0)\end{array}$ & $\begin{array}{c}\mathrm{W} \\
(0 \sim 1)\end{array}$ & $\begin{array}{l}\text { Agreement from } \\
{[- \text { nas }] \text { to }[+ \text { nas }]}\end{array}$ \\
\hline$\sim c$. & $\begin{array}{l}{[\mathrm{bet}]} \\
\mathcal{R}:\{\mathrm{b} \mathrm{t}\}\end{array}$ & & $\begin{array}{c}\mathrm{W} \\
(0 \sim 1)\end{array}$ & & $\begin{array}{c}\mathrm{L} \\
(1 \sim 0)\end{array}$ & & $\begin{array}{l}\text { Agreement from } \\
{[- \text { nas }] \text { to }[+ \text { nas }]}\end{array}$ \\
\hline$\sim \mathrm{d}$. & $\begin{array}{l}{[\text { ben }],} \\
\mathcal{R}:\{\mathrm{b}\}\{\mathrm{n}\}\end{array}$ & & & $\begin{array}{c}\mathrm{W} \\
(0 \sim 1)\end{array}$ & $\begin{array}{c}\mathrm{L} \\
(1 \sim 0)\end{array}$ & & $\begin{array}{c}\text { No corresp., no } \\
\text { agreement }\end{array}$ \\
\hline
\end{tabular}

The winning candidate in (a) is fully faithful; it keeps /ben/ as [ben], and has correspondence between the onset and coda, but does not repair the nasal disagreement between them - it violates CC.IDENT-[nasal]. The alternatives in (b) and (c) do fix this disagreement, and satisfy $\mathrm{CC} \cdot$ IDENT-[nasal], but are ruled out by higher constraints. In (b), agreement is obtained by nasalising the onset $/ \mathrm{b} /$ to $[\mathrm{m}]$, making it match the [+nasal] of the coda; however, this violates IDENT-Onset-[-nasal]. In (c), nasal agreement is obtained in the opposite fashion, by denasalising the coda $/ \mathrm{n} /$ to [ $\mathrm{t}]$ to make it match the [-nasal] onset. This, however, means violating IDENT-[+nasal], which is also ranked higher than the harmony constraints. The result is that the 
optimal candidate simply tolerates disagreement; the only ways to fix it are worse over the ranking as a whole 5 .

So, the result that comes from the ranking in (27) is that although nasal agreement is always preferred, it isn't always optimal. The constraints IDENT-Onset-[-nasal] and IDENT-[+nasal] impose restrictions on what kinds of changes are worth making in order to achieve agreement. When these limits are strict enough, disagreement may be tolerated in some situations, and repaired in others. The point is that stringent limitations on a mandate for agreement make it look like it's not bidirectional agreement, but rather a one-way dependency. But, the dependency pattern is a straightforward outcome of how the constraints interact, and doesn't require any special theoretical machinery to distinguish it from agreement.

\subsection{The direction of the agreement}

The other still-unresolved facet of the analysis is the direction of agreement: why should illicit /NVT/ inputs be repaired to [NVN] instead of [TVT]? In other words, why do agreement by nasalising, and not by de-nasalising? The answer turns out to fall out for free from the account of TVN inputs. Changing $/ \mathrm{n} /$ to [t] violates IDENT-[+nasal]; changing $/ \mathrm{t} /$ to $[\mathrm{n}]$ violates IDENT[-nasal]. So, if we are faced with a choice between one change and the other, the better option will be the one that violates the lower of the two IDENT constraints. The ranking given in (27) requires that IDENT-[+nasal] dominates the harmony constraints, and IDENT-[-nasal] is dominated by them. It therefore follows that IDENT-[+nasal] is ranked higher than IDENT-[-nasal]. Thus, the ranking needed to stop /TVN/ syllables from undergoing assimilation also determines what kind of assimilation must be used in the situations where agreement does happen.

The tableau in (29) shows how this works. The input is a hypothetical form /nap/ which is not permitted on the surface, and must be changed. The winning candidate in (a) fixes it by nasalising the $/ \mathrm{p} /$ to $[\mathrm{m}]$; this violates only IDENT-[-nasal]. The alternative in (b) instead changes the onset $/ \mathrm{n} /$ to [t], which violates IDENT-[+nasal]. Since IDENT-[+nasal] dominates IDENT-[nasal], (a) wins.

(29) Ranking from (27) also determines the direction of assimilation

\begin{tabular}{|c|c|c|c|c|c|c|}
\hline \multicolumn{2}{|c|}{$\begin{array}{l}\text { Input: nap } \\
\text { Output: nam }\end{array}$} & $\begin{array}{c}\text { IDENT-Onset- } \\
\text { [-nasal] }\end{array}$ & $\begin{array}{c}\text { IDENT- } \\
{[+ \text { nasal] }}\end{array}$ & $\begin{array}{c}\text { CORR-CVC. } \\
{[- \text { continuant }]}\end{array}$ & $\begin{array}{c}\text { CC } \cdot \text { IDENT- } \\
\text { [nasal] }\end{array}$ & $\begin{array}{l}\text { IDENT- } \\
\text { [-nasal] }\end{array}$ \\
\hline$\leftrightarrow a$. & $\begin{array}{l}{[\mathrm{nam}],} \\
\mathcal{R}:\{\mathrm{n} \mathrm{m}\}\end{array}$ & (0) & (0) & (0) & (0) & (1) \\
\hline$\sim b$. & $\begin{array}{l}{[\mathrm{tap}]} \\
\mathcal{R}:\{\mathrm{t} \mathrm{p}\}\end{array}$ & & $\begin{array}{c}W \\
(0 \sim 1)\end{array}$ & & & $\begin{array}{c}\mathrm{L} \\
(1 \sim 0)\end{array}$ \\
\hline
\end{tabular}

\footnotetext{
${ }^{5}$ The candidate in (28d) is also fully faithful, and differs from (28a) only in terms of correspondence. It is shown here as ruled out by CORR-CVC $\cdot[-$ continuant $]$. This isn't entirely crucial, though: reversing the relative ranking between the two harmony constraints changes which of the two fully faithful candidates wins. Both interpretations are equally consistent with the data given here.
} 


\section{Why a local spreading analysis doesn't work}

The account proposed above requires the theoretical machinery of Surface Correspondence. Those who are wont to invoke Occam's Razor might argue that this is undesirable, since an alternative analysis based on local spreading doesn't require this elaboration of the theory of phonology.

The correspondence machinery used here doesn't otherwise appear to be necessary to explain Obolo, but it is independently motivated by assimilation and dissimilation patterns in other languages. It is also warranted for this case, because a simple spreading account simply doesn't get the facts right, as this section will show.

For a spreading-based analysis of Obolo, instead of using two correspondence constraints (CC.IDENT and CORR), we would have a single constraint that favours spreading, like the one in (30) (modelled after Walker 1998).

(30) SPREAD-R([+nasal], $\sigma):$ 'Spread [+nasal] rightward within the syllable' $D f n$ : For each distinct pair of two output segments, $\mathrm{X} \& \mathrm{Y}$, assign a violation if:
a. $\quad \mathrm{X} \& \mathrm{Y}$ are in the same syllable, $\sigma$
and
b. $\mathrm{X}$ precedes $\mathrm{Y}$,
and
c. $\mathrm{X}$ is associated to an instance, $\mathrm{F}$, of the feature [+nasal], and
d. $\quad \mathrm{Y}$ is not associated to $\mathrm{F}$ (i.e. to the same instance of [+nasal])

A spreading constraint like this can correctly derive the ban on [NVT] syllables, in more or less the same way as the Surface Correspondence approach. If [+nasal] features must spread to the right edge of any syllable they are in, then inputs like /nap/ will be turned into [nãm], as in (31). The winning candidate in (a) spreads [+nasal] from the $/ \mathrm{n} /$ to both the following $/ \mathrm{a} /$, and the coda $/ \mathrm{p} /$, and each successive increment of spreading reduces the number of SPREAD-R violations incurred, as the [+nasal] feature gets closer to the right edge of the syllable. (The candidate in (d) also satisfies SPREAD-R by removing the misaligned [+nasal] feature, but this is eliminated by having IDENT-[+nasal] dominating IDENT-[-nasal], just as in the Surface Correspondence analysis.)

(31) Rightward local spreading can turn /nap/ into [nãm]

\begin{tabular}{|c|c|c|c|c|}
\hline \multicolumn{2}{|c|}{$\begin{array}{l}\text { Input: nap } \\
\text { Output: nãm }\end{array}$} & IDENT-[+nasal] & SPREAD-R([+nasal $], \sigma)$ & IDENT-[-nasal] \\
\hline a. & $\begin{array}{c}{[\mathrm{n} \tilde{a} \mathrm{~m}]} \\
\bigvee / \\
{[+\mathrm{N}]}\end{array}$ & (0) & (0) & (2) \\
\hline$\sim b$. & $\begin{array}{c}{[\mathrm{n} \text { a p }]} \\
/ \backslash \backslash \\
{[+\mathrm{N}][-\mathrm{N}]}\end{array}$ & & $\begin{array}{c}W \\
(0 \sim 2)\end{array}$ & $\begin{array}{c}\mathrm{L} \\
(2 \sim 0)\end{array}$ \\
\hline$\sim \mathrm{C}$. & $\begin{array}{c}{[\mathrm{n} \text { ã p] }} \\
\left.|/|{ }^{2} \mid \mathrm{N}\right][-\mathrm{N}]\end{array}$ & & $\begin{array}{c}W \\
(0 \sim 1)\end{array}$ & $\begin{array}{c}\mathrm{L} \\
(2 \sim 1)\end{array}$ \\
\hline$\sim d$. & $\begin{array}{c}{[\mathrm{t} \text { a p }]} \\
\mid / / \\
{[-\mathrm{N}]}\end{array}$ & $\begin{array}{c}\mathrm{W} \\
(0 \sim 1)\end{array}$ & & $\begin{array}{c}\mathrm{L} \\
(2 \sim 0)\end{array}$ \\
\hline
\end{tabular}


Where the spreading analysis goes wrong is the treatment of open syllables. Primary descriptions of Obolo report that vowels get nasalised before a nasal consonant (Faraclas 1984:xix). But, they don't report nasalisation of vowels after a nasal consonant. This is illustrated in (32) (Faraclas 1982:72).

$$
\begin{aligned}
& \text { [ãmewa] 'many towns' (</ámà/ 'town' + /̂̂-wa/ '3.sbj-exist') } \\
& \text { *[ãmẽwa]; no nasalisation on the }[\mathrm{e}] \text { that follows }[\mathrm{m}]
\end{aligned}
$$

The spreading constraint predicts nasal spreading in open syllables, though, as illustrated by the tableau in (33): the data tells us we should get winners like (a), but SPREAD-R([+nasal], $\sigma)$ favours the loser (b) instead (marked with a frowning face because the ranking predicts that it wins, even though it shouldn't).

\begin{tabular}{|c|c|c|c|c|}
\hline \multicolumn{2}{|c|}{ Input: ama } & IDENT-[+nasal] & SPREAD-R([+nasal], $\sigma)$ & IDENT-[-nasal] \\
\hline$(\circledast) \mathrm{a}$. & $\left.\right|_{[+\mathrm{N}][+\mathrm{N}][-\mathrm{N}]} ^{[\tilde{\mathrm{a}} \mathrm{m} \mathrm{a}]}$ & (0) & (1) & (0) \\
\hline (:) b. & $\begin{array}{c}{[\tilde{a} . \mathrm{m} \tilde{a}]} \\
|\backslash| \mathrm{N}] \\
{[+\mathrm{N}]}\end{array}$ & & $\begin{array}{c}\mathrm{L} \\
(1 \sim 0)\end{array}$ & $\begin{array}{c}W \\
(0 \sim 1)\end{array}$ \\
\hline
\end{tabular}

SPREAD-R([+nasal], $\sigma)$ predicts nasalisation of post-nasal vowels

The point here is that while a spreading analysis is very intuitive, and at first glance even seems to fit the data, it's actually wrong. The distribution of nasality that we find in Obolo doesn't follow from incremental local spreading; it necessitates a long-distance interaction between the consonants, as the Surface Correspondence theory posits.

\section{Conclusion and extensions}

\subsection{Summary and conclusions}

The aim of this paper has been to show how the Surface Correspondence theory analyses a pattern of nasal agreement found in Obolo, and to show that the one-way 'dependency' aspect of this agreement can still be explained in essentially the same way as other cases of consonant harmony. The generalisation that disagreement $i s$ permitted on the surface falls out as a natural consequence of different restrictions on how assimilation can operate. If the featural 'direction' of assimilation is restricted (assimilation can't change underlying [ + nasal] consonants), and the position it can apply to is also restricted (onsets do not assimilate), the result is a system where agreement is applied in some forms, while other disagreeing forms are unfixable and thus emerge faithfully.

Agreement patterns like the one seen in Obolo are often extremely subtle, and don't leap out as obvious examples of long-distance consonant harmony. In the Obolo case specifically, this is because there are no visible alternations: because the interacting consonants are not very far apart; because agreement between them isn't enforced in all cases; and because when they do agree, it affects the intervening material. In short, then, Obolo is very much a non-canonical example of long-distance consonant agreement. The fact that it follows from the Surface 
Correspondence theory anyway shows that the theory has broader explanatory adequacy than previous work envisioned. Additionally, a conventional diagnostic for correspondence-driven phenomena is lack of an effect on intervening material. The present analysis illustrates that this diagnostic is not sufficient: the same theory of correspondence also extends naturally to cases where agreement between non-adjacent segments does affect intervening material.

\subsection{Generalising to other cases: an example from Afrikaans}

The account of the agreement dependency in Obolo can be straightforwardly extended to some other languages with agreement dependencies. As an example, let us consider voicing patterns in Afrikaans, as documented by Coetzee (2014). Coetzee reports that CVC roots may not have a contrastively [-voice] consonant in initial position and a contrastively [+voice] one in final position. That is, words like [tad] are impossible; they are a gap in the lexicon, and speakers avoid positing /TVD/ underlying forms for nonce forms consistent with this interpretation.

The Afrikaans voicing pattern is a dependency, in much the same way as what we find in Obolo. The generalisation is that if the second consonant in a CVC root is voiced, then the first one is also voiced ${ }^{6}$. This is an implication, like in Obolo: a particular (and marked) feature is permitted in non-initial position only if it is also present in initial position. Similar implicational patterns are also reported as morpheme structure constraints on roots in many other languages, involving other features; for a few examples, see aspirates and ejectives in Aymara (MacEachern 1999, Mackenzie 2009), laryngeally-marked obstruents in Zulu (Khumalo 1987), and coronal harmony in Pengo (Arsenault 2012).

To see how the Surface Correspondence theory helps explain patterns like this, let us first consider the constraint ranking in (34). The effect of this ranking is positional neutralisation, in the sense of Lombardi (1999). Because *[+voice] dominates general faithfulness for voicing, voicing is generally neutralised. However, voiced consonants in root-initial position are protected from this neutralisation by the positional faithfulness constraint IDENT-Initial-[+voice]. So, noninitial consonants neutralise to [-voice], but initial [+voice] consonants are permitted. The tableau in (35) illustrates this result. The winning candidate in (a) reduces only the non-initial / $d /$ to [t]; this avoids one violation of $*$ [+voice] (cf. b), while also still satisfying IDENT-Initial[+voice] (cf. b).

\footnotetext{
${ }^{6}$ There are a few other details to the Afrikaans pattern that I will not try to account for here. For one, CVC roots aren't always parsed as a single syllable. Final devoicing in Afrikaans means that /TVD/ roots would surface as [TVT] in some contexts (e.g. as singular nouns); the status of the second consonant as voiced is only evident when vowel-initial suffixes follow. I don't try to account for final devoicing; see Coetzee (2014) for details of how this was controlled for in diagnosing the restriction. Also, the generalisation holds only over roots that are CVC in shape; there are some CVCV roots that don't follow the same pattern. Finally, the dependency generalisation of interest here holds only over consonants where [ \pm voice] is contrastive: CVC roots may combine a final voiced obstruent with an initial voiced sonorant, or with a voiceless obstruent that lacks a voiced counterpart (e.g. /x/, which has no counterpart /y/).
} 
(34) Positional neutralisation ranking: IDENT-Initial-[+voice] $» *[+$ voice $] »$ IDENT-[+voice]

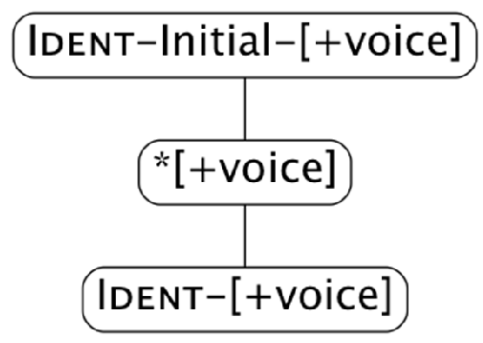

(35) Neutralisation for non-initial voiced consonants only

\begin{tabular}{|c|l|c|c|c|}
\hline \multicolumn{1}{|l|}{$\begin{array}{l}\text { Input: dad } \\
\text { Output: dat }\end{array}$} & $\begin{array}{c}\text { IDENT-Initial- } \\
\text { [+voice] }\end{array}$ & $*$ [+voice] & $\begin{array}{c}\text { IDENT- } \\
\text { [+voice] }\end{array}$ \\
\hline$\sim$ a. & dat & $(0)$ & $(1)$ & $(1)$ \\
\hline$\sim$ b. & dad & & $\mathrm{W}$ & $\mathrm{L}$ \\
$(1 \sim 2)$ & $(1 \sim 0)$ \\
\hline$\sim$ c. & tat & $\mathrm{W}$ & $\mathrm{L}$ & $\mathrm{W}$ \\
$(0 \sim 1)$ & $(1 \sim 0)$ & $(1 \sim 2)$ \\
\hline
\end{tabular}

(36) *[+voice] can be overruled by agreement as well as faithfulness

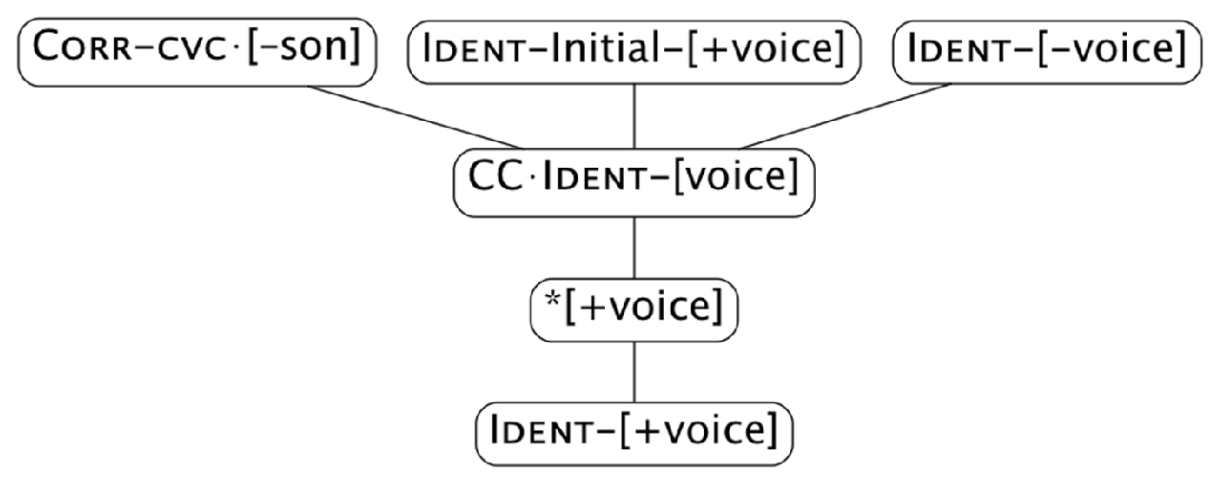

The structure of the ranking is very much like the one we found in Obolo, and its consequences are accordingly similar. CC·IDENT-[voice] and CORR-CVC $\cdot[-$ sonorant] favour agreement among obstruents in voicing, just like how CORR-CVC·[-cont] and CC.IDENT-[nasal] favour nasal agreement among non-continuants in Obolo. Also like in Obolo, the undominated faithfulness constraints put limits on assimilation: agreement will not force initial [+voice] obstruents to devoice (the effect of IDENT-Initial-[+voice]), and will not force underlying voiceless consonants to become voiced (the effect of IDENT-[-voice]). This means that underlying /DVT/ inputs surface faithfully (37), tolerating disagreement rather than violating the limitations imposed by the undominated IDENT constraints - much like the TVN syllables in Obolo. 
(37) No agreement enforced in /DVT/ inputs

\begin{tabular}{|c|c|c|c|c|c|c|c|}
\hline \multicolumn{2}{|c|}{$\begin{array}{l}\text { Input: dat } \\
\text { Output: dat }\end{array}$} & $\begin{array}{c}\text { IDENT-Initial- } \\
\text { [+voice }]\end{array}$ & $\begin{array}{c}\text { IDENT- } \\
\text { [-voice }]\end{array}$ & $\begin{array}{c}\text { CORR-CVC. } \\
{[\text {-sonorant] }}\end{array}$ & $\begin{array}{c}\text { CC } \cdot \text { IDENT- } \\
\text { [voice] }\end{array}$ & $*[+$ voice $]$ & $\begin{array}{c}\text { IDENT- } \\
\text { [+voice }]\end{array}$ \\
\hline a. & $\begin{array}{l}{[\mathrm{dat}]} \\
\mathcal{R}:\{\mathrm{d} \mathrm{t}\}\end{array}$ & (0) & (0) & (0) & (1) & (1) & (0) \\
\hline$\sim \mathrm{b}$ & $\begin{array}{l}{[\mathrm{dad}]} \\
\mathcal{R}:\{\mathrm{d} \mathrm{d}\}\end{array}$ & & $\begin{array}{c}\mathrm{W} \\
(0 \sim 1)\end{array}$ & & $\begin{array}{c}\mathrm{L} \\
(1 \sim 0)\end{array}$ & $\begin{array}{c}\mathrm{W} \\
(1 \sim 2)\end{array}$ & \\
\hline$\sim c$. & $\begin{array}{l}{[\mathrm{tat}]} \\
\mathcal{R}:\{\mathrm{t} t\}\end{array}$ & $\begin{array}{c}\mathrm{W} \\
(0 \sim 1)\end{array}$ & & & $\begin{array}{c}\mathrm{L} \\
(1 \sim 0)\end{array}$ & $\begin{array}{c}\mathrm{L} \\
(1 \sim 0)\end{array}$ & $\begin{array}{c}W \\
(0 \sim 1)\end{array}$ \\
\hline$\sim \mathrm{d}$ & $\begin{array}{l}{[\mathrm{dat}]} \\
\mathcal{R}:\{\mathrm{d}\}\{\mathrm{t}\}\end{array}$ & & & $\begin{array}{c}\mathrm{W} \\
(0 \sim 1)\end{array}$ & $\begin{array}{c}\mathrm{L} \\
(1 \sim 0)\end{array}$ & $\begin{array}{c}\mathrm{e} \\
(1 \sim 1)\end{array}$ & \\
\hline
\end{tabular}

What agreement will do, however, is override the general avoidance of [+voice] in non-initial positions. By locally over-ruling the effect of *[+voice], the agreement constraint inhibits neutralisation when it would result in a disagreeing sequence. This is illustrated in (38).

(38) Agreement blocks neutralisation: non-initial /d/ is faithful when it follows another faithful /d/ in initial position

\begin{tabular}{|c|c|c|c|c|c|c|c|}
\hline \multicolumn{2}{|c|}{$\begin{array}{l}\text { Input: dadə } \\
\text { Output: dadə }\end{array}$} & $\begin{array}{c}\text { IDENT-Initial- } \\
\text { [+voice }]\end{array}$ & $\begin{array}{c}\text { IDENT- } \\
\text { [-voice }]\end{array}$ & $\begin{array}{c}\text { CORR-CVC } \cdot \\
\text { [-sonorant }]\end{array}$ & $\begin{array}{c}\text { CC } \cdot \text { IDENT- } \\
\text { [voice }]\end{array}$ & $*[+$ voice $]$ & $\begin{array}{c}\text { IDENT- } \\
\text { [+voice }]\end{array}$ \\
\hline a. & $\begin{array}{l}{[\mathrm{dad} \partial]} \\
\mathcal{R}:\{\mathrm{d} \mathrm{d}\}\end{array}$ & (0) & (0) & (0) & (0) & (2) & (0) \\
\hline$\sim b$. & $\begin{array}{l}{[\text { dat }],} \\
\mathcal{R}:\{\mathrm{d} \mathrm{t}\}\end{array}$ & & & & $\begin{array}{c}W \\
(0 \sim 1)\end{array}$ & $\begin{array}{c}\mathrm{L} \\
(2 \sim 1)\end{array}$ & $\begin{array}{c}W \\
(0 \sim 1)\end{array}$ \\
\hline$\sim \mathrm{C}$. & $\begin{array}{l}{[\text { dat }],} \\
\mathcal{R}:\{\mathrm{d}\}\{\mathrm{t}\}\end{array}$ & & & $\begin{array}{c}W \\
(0 \sim 1)\end{array}$ & & $\begin{array}{c}\mathrm{L} \\
(2 \sim 1)\end{array}$ & $\begin{array}{c}\mathrm{W} \\
(0 \sim 1)\end{array}$ \\
\hline$\sim \mathrm{d}$. & $\begin{array}{l}{[\text { tato }]} \\
\mathcal{R}:\{\mathrm{t} t\}\end{array}$ & $\begin{array}{c}W \\
(0 \sim 1)\end{array}$ & & & & $\begin{array}{c}\mathrm{L} \\
(2 \sim 0)\end{array}$ & $\begin{array}{l}\mathrm{W} \\
(0 \sim 2)\end{array}$ \\
\hline
\end{tabular}

The winning candidate in (38a) above has two voiced consonants, and retains both; the noninitial /d/ does not devoice to [t] as would otherwise be expected. The reason is that this reduction leads to an agreement problem: the resulting [d...t] sequence either violates CC.IDENT-[voice], or violates CORR-CVC·[-sonorant]. A further option would be to have devoicing "feed" agreement, leading to a [t...t] sequence like (d), but this is ruled out by initial faithfulness. The outcome, then, is that positional neutralisation fails in precisely that situation where the result would violate agreement. This leads to exactly the sort of dependency we observe: the second consonant can be voiced only if the first consonant is also voiced. Without having this agreement, there is no impetus not to devoice. In effect, the agreement constraints extend the protection of the [+voice] consonant in initial position to another [+voice] consonant later on. If the initial consonant is not voiced, though, the same ranking does produce neutralisation, as illustrated in (39) with a hypothetical input/tadə/. 
(39) Agreement does not protect [+voice] in /TVD/ inputs

\begin{tabular}{|c|c|c|c|c|c|c|c|}
\hline \multicolumn{2}{|c|}{$\begin{array}{l}\text { Input: tadə } \\
\text { Output: tatə }\end{array}$} & $\begin{array}{c}\text { IDENT-Initial- } \\
\text { [+voice }]\end{array}$ & $\begin{array}{c}\text { IDENT- } \\
{[\text {-voice }]}\end{array}$ & $\begin{array}{c}\text { CORR-CVC. } \\
\text { [-sonorant] }\end{array}$ & $\begin{array}{l}\text { CC } \cdot \text { IDENT- } \\
\text { [voice }]\end{array}$ & $*[+$ voice $]$ & $\begin{array}{c}\text { IDENT- } \\
\text { [+voice] }\end{array}$ \\
\hline$\leftrightarrow$ a. & $\begin{array}{l}{[\text { tatə], }} \\
\mathcal{R}:\{\mathrm{t} \mathrm{t}\}\end{array}$ & (0) & (0) & L & (0) & (0) & (1) \\
\hline$\sim b$. & $\begin{array}{l}{[\mathrm{tad} \partial]} \\
\mathcal{R}:\{\mathrm{t} \mathrm{d}\}\end{array}$ & & 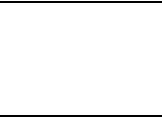 & 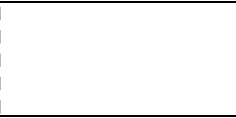 & $\begin{array}{c}\mathrm{W} \\
(0 \sim 1)\end{array}$ & $\begin{array}{c}\mathrm{W} \\
(0 \sim 1)\end{array}$ & $\begin{array}{c}\mathrm{L} \\
(1 \sim 0) \\
\end{array}$ \\
\hline$\sim \mathrm{C}$. & $\begin{array}{l}\text { [tadə], } \\
\mathcal{R}:\{\mathrm{t}\}\{\mathrm{d}\}\end{array}$ & & & $\begin{array}{c}\mathrm{W} \\
(0 \sim 1)\end{array}$ & & $\begin{array}{c}W \\
(0 \sim 1)\end{array}$ & $\begin{array}{c}\mathrm{L} \\
(1 \sim 0)\end{array}$ \\
\hline$\sim \mathrm{d}$ & $\begin{array}{l}{[\mathrm{dad} \partial]} \\
\mathcal{R}:\{\mathrm{d} \mathrm{d}\}\end{array}$ & & $\begin{array}{c}W \\
(0 \sim 1)\end{array}$ & & & $\begin{array}{c}W \\
(0 \sim 2)\end{array}$ & $\begin{array}{c}W \\
(0 \sim 2)\end{array}$ \\
\hline
\end{tabular}

The analysis sketched out here admittedly doesn't capture all the details of the Afrikaans pattern, but it does derive the right kind of dependency effect. The ranking from (36) permits a non-initial voiced consonant only when the initial consonant is also voiced. The agreement isn't observed as an active pattern: neither /DVT/ nor /TVD/ inputs surface with assimilation for [+voice]. Instead, the role the agreement constraints play in the system is much more subtle: they stop the otherwise-systematic neutralisation of word-medial voiced obstruents in roots where this would lead to disagreement. The result is an implicational dependency: a medial consonant can be voiced if that means it agrees in voicing with the initial consonant where that contrast is normally licensed. This outcome is an emergent result of the kinds of constraints posited in the Surface Correspondence theory, and doesn't require any further stipulation about licensing of features or alignment. The point here is that the theory is applicable even to patterns that don't fit the traditional profile of long-distance consonant harmony.

\section{Acknowledgements}

I owe thanks to Akin Akinlabi for valuable input on several previous iterations of this work, as well as to Alan Prince, Bruce Tesar, Sharon Rose, and Andries Coetzee for helpful discussion, and to audiences at SAMWOP-2 and the 2014 LSA annual meeting. An earlier version of portions of this analysis appears in Bennett (2013). Any errors are my own.

\section{References}

Aaron, U.E. 1996/1997a. The category of number in Obolo verbal morphology. Journal of West African Languages 26(1): 49-76.

Aaron, U.E. 1996/1997b. Grammaticization of the verb 'say' to future tense in Obolo. Journal of West African Languages 26(2): 87-93.

Ao, B. 1991. Kikongo nasal harmony and context-sensitive underspecification. Linguistic Inquiry 22(1): 193-196. 
Arsenault, P.E. 2012. Retroflex Consonant Harmony in South Asia. PhD thesis, University of Toronto.

Baković, E. 2000. Harmony, Dominance and Control. PhD thesis, Rutgers University, New Brunswick, NJ.

Beckman, J.N. 1998. Positional Faithfulness. PhD thesis, University of Massachusetts, Amherst.

Bennett, Wm.G. 2013. Dissimilation, Consonant Harmony, and Surface Correspondence. PhD thesis, Rutgers University, New Brunswick, NJ.

Coetzee, A.W. 2014. Grammatical change through lexical accumulation: Voicing cooccurrence restrictions in Afrikaans. Language 90(3): 693-721.

Faraclas, N. 1982. Elision and other morpheme boundary phenomena in the western dialects of Obolo. The Journal of West African Languages 12(2): 69-82.

Faraclas, N. 1984. A grammar of Obolo. Bloomington: Indiana University Linguistics Club.

Fivaz, D. and S. Shikomba. 1986. A reference grammar of Oshindonga. Windhoek: The Academy, Department of African Languages.

Gafos, A.I. 1999. The articulatory basis of locality in phonology. New York: Garland Publishing Inc.

Hansson, G.Ó. 2010a. Consonant harmony: Long-distance interaction in phonology. University of California Publications in Linguistics 145. Berkeley, CA: University of California Press.

Hansson, G.Ó. 2010b. Long-distance voicing assimilation in Berber: Spreading and/or agreement? In M. Heijl (ed.) Proceedings of the 2010 annual conference of the Canadian Linguistic Association. Montréal: Canadian Linguistic Association. Available online: http://homes.chass.utoronto.ca/ cla-acl/actes2010/CLA2010_Hansson.pdf (Accessed 4 September 2014).

Khumalo, J.S.M. 1987. An Autosegmental Account of Zulu Phonology. PhD thesis, University of the Witwatersrand.

Kimenyi, A. 1979. Studies in Kinyarwanda and Bantu phonology. Alberta, Canada: Linguistic Research Inc.

Lombardi, L. 1999. Positional faithfulness and voicing assimilation in Optimality Theory. Natural Language and Linguistic Theory 17(2): 267-302.

MacEachern, M. 1999. Laryngeal co-occurrence restrictions. New York: Garland Publishing Inc. 
Mackenzie, S. 2009. Contrast and Similarity in Consonant Harmony Processes. PhD thesis, University of Toronto.

McCarthy, J.J. and A. Prince. 1999. Faithfulness and identity in prosodic morphology. In R. Kager, H. van der Hulst and W. Zonneveld (eds.) The prosody-morphology interface. Cambridge: Cambridge University Press. pp. 218-309.

Ní Chiosáin, M. and J. Padgett. 2001. Markedness, segment realization, and locality in spreading. In L. Lombardi (ed.) Segmental phonology in Optimality Theory. Cambridge: Cambridge University Press. pp. 118-156.

Pater, J. 1999. Austronesian nasal substitution and other NÇ effects. In R. Kager, H. van der Hulst and W. Zonneveld (eds.) The prosody-morphology interface. Cambridge: Cambridge University Press. pp. 310-343.

Prince, A. 2002. Arguing optimality. In A. Coetzee, A. Carpenter and P. de Lacy (eds.) Papers in Optimality Theory II. University of Massachusetts, Amherst: GLSA. pp. 269-304.

Prince, A. and P. Smolensky. 2004. Optimality Theory: Constraint interaction in Generative Grammar. Cambridge, MA: MIT Press.

Rose, S. and R. Walker. 2004. A typology of consonant agreement as correspondence. Language 80: 475-531.

Rowland-Oke, M. 2003. Description systématique de la langue Obolo-Andoni: Langue du groupe Cross River. L'Harmattan: Paris.

Walker, R. 1998. Nasalization, Neutral Segments, and Opacity Effects. PhD thesis, University of California, Santa Cruz.

Walker, R. 2000. Yaka nasal harmony: Spreading or segmental correspondence? Proceedings of the Annual Meeting of the Berkeley Linguistics Society 26(1): 321-332.

Walker, R., D. Byrd and F. Mpiranya. 2008. An articulatory view of Kinyarwanda coronal harmony. Phonology 25(3): 499-535. 